\title{
Video Scanning Hartmann Optical Testing of State-of- the-Art Parabolic Trough Concentrators
}

\section{Preprint}

T. Wendelin

National Renewable Energy Laboratory

K. May

Industrial Solar Technology

R. Gee

Solargenix

To be presented at Solar 2006 Conference (ISEC '06) Denver, Colorado July 8-13, 2006

Conference Paper NREL/CP-550-39590 June 2006 


\section{NOTICE}

The submitted manuscript has been offered by an employee of the Midwest Research Institute (MRI), a contractor of the US Government under Contract No. DE-AC36-99G010337. Accordingly, the US Government and MRI retain a nonexclusive royalty-free license to publish or reproduce the published form of this contribution, or allow others to do so, for US Government purposes.

This report was prepared as an account of work sponsored by an agency of the United States government. Neither the United States government nor any agency thereof, nor any of their employees, makes any warranty, express or implied, or assumes any legal liability or responsibility for the accuracy, completeness, or usefulness of any information, apparatus, product, or process disclosed, or represents that its use would not infringe privately owned rights. Reference herein to any specific commercial product, process, or service by trade name, trademark, manufacturer, or otherwise does not necessarily constitute or imply its endorsement, recommendation, or favoring by the United States government or any agency thereof. The views and opinions of authors expressed herein do not necessarily state or reflect those of the United States government or any agency thereof.

Available electronically at http://www.osti.gov/bridge

Available for a processing fee to U.S. Department of Energy and its contractors, in paper, from:

U.S. Department of Energy

Office of Scientific and Technical Information

P.O. Box 62

Oak Ridge, TN 37831-0062

phone: 865.576.8401

fax: 865.576 .5728

email: mailto:reports@adonis.osti.gov

Available for sale to the public, in paper, from:

U.S. Department of Commerce

National Technical Information Service

5285 Port Royal Road

Springfield, VA 22161

phone: 800.553 .6847

fax: 703.605.6900

email: orders@ntis.fedworld.gov

online ordering: http://www.ntis.gov/ordering.htm 
ISEC2006-99172

\title{
VIDEO SCANNING HARTMANN OPTICAL TESTING OF STATE-OF-THE-ART PARABOLIC TROUGH CONCENTRATORS
}

\author{
Tim Wendelin \\ National Renewable Energy Laboratory \\ Golden, CO
}

\author{
Ken May \\ Industrial Solar Technology \\ Golden, CO
}

\author{
Randy Gee \\ Solargenix \\ Arvada, CO
}

\begin{abstract}
Significant progress has been made recently in solar parabolic trough technology development and deployment. Part of this success is due to the changing world energy scenario, and the recognition that viable renewable energy technologies can play a role in supplying world energy needs. Part is also due to ongoing collaborative efforts by industry and the concentrating solar power subprogram (CSP) of the Department of Energy's (DOE) Solar Energy Technologies Program to enhance the state of the technology in terms of both cost and performance. Currently, there are two trough concentrator projects that the DOE CSP subprogram is supporting. One company, Solargenix, is developing a design to be used in a 64MW plant outside of Boulder City, Nevada. This design is based on the original LUZ LS-2 trough concentrators employed at the Solar Electric Generating Systems (SEGS) plants in Southern California. Another company, Industrial Solar Technology (IST), is working on a scaleup of their design used historically for process heat applications. Very different from the LS-2 approach, this design is still in the research and development stages. One way in which the DOE CSP parabolic trough research assists industry is by providing optical testing and qualification of their concentrator designs. This paper describes the Video Scanning Hartmann Optical Test System (VSHOT) used to optically test both of these designs. This paper also presents the results of tests performed in the past year, and what impact the testing has had on the developmental direction of each design.
\end{abstract}

\author{
NOMENCLATURE \\ $X=$ coordinate along parabolic trough length \\ $\mathrm{Y}=$ coordinate across parabolic trough aperture \\ $\mathrm{Z}=$ direction of parabolic trough optical axis \\ $\mathrm{k}=$ number of VSHOT data points \\ $B_{i, j}=$ coefficients of mathematical equation used to \\ describe surface contour \\ $f_{y}=$ focal length of trough
}

\section{INTRODUCTION}

Over the past two years, significant progress has been made in the development and deployment of solar parabolic trough technology. This progress has been driven in part by the rapidly changing world energy scenario, and the recognition that viable renewable energy technologies can play a role in supplying global energy needs. It is also due to ongoing collaborative efforts by industry and the concentrating solar power subprogram (CSP) of the Department of Energy's (DOE) Solar Energy Technologies Program to enhance the state of the technology by reducing cost and increasing performance. Currently, there are two industry trough concentrator development efforts that the DOE CSP subprogram is supporting.

Solargenix is developing a concentrator to be used in a $64 \mathrm{MW}$ plant outside of Boulder City, Nevada. This concentrator geometry is roughly patterned after the LUZ LS-2 trough concentrators employed at the Solar Electric Generating Systems (SEGS) plants in Southern 
California. Solargenix recently built a $1 \mathrm{MW}$ Organic Rankine Cycle plant for Arizona Public Service that utilizes the first generation of their concentrator design. The 64 MW plant, scheduled for completion in early 2007, will utilize the next generation design. Solargenix has a subcontract with the National Renewable Energy Laboratory (NREL) as part of DOE's CSP subprogram to assist them in the development and deployment of their technology.

Industrial Solar Technology Corporation (IST), is working on a scale-up of their concentrator, which they designed originally for process heat applications. This design differs significantly from the LS-2 approach, and is still in the research and development stages. IST also has a subcontract with NREL to help in the development of their technology.

Another way in which the DOE CSP parabolic trough research assists industry is by providing optical testing and qualification of their concentrator designs. Specifically over the last year, the Video Scanning Optical Test System (VSHOT) has been used to optically test multiple versions of the Solargenix concentrator as well as the IST baseline design. This paper describes the VSHOT system as it relates to trough concentrators and presents the Solargenix and IST test results for the past year and what impact this testing has had on the developmental direction of each design.

\section{VSHOT DESCRIPTION}

The VSHOT is a laser ray trace system designed to characterize the optical surfaces of solar concentrators. Originally designed to test point-focus concentrators $^{1}$ (sometimes referred to as dish concentrators), it has been modified to include optical characterization of line-focus (or trough) concentrators. Changes have also been made to increase the speed and improve the functionality of the system in the field. The VSHOT utilizes computer-controlled laser scanning and digital camera image acquisition to provide optical surface contour data and mathematical/statistical surface representation.

Figure 1 illustrates schematically the VSHOT system in 2D.

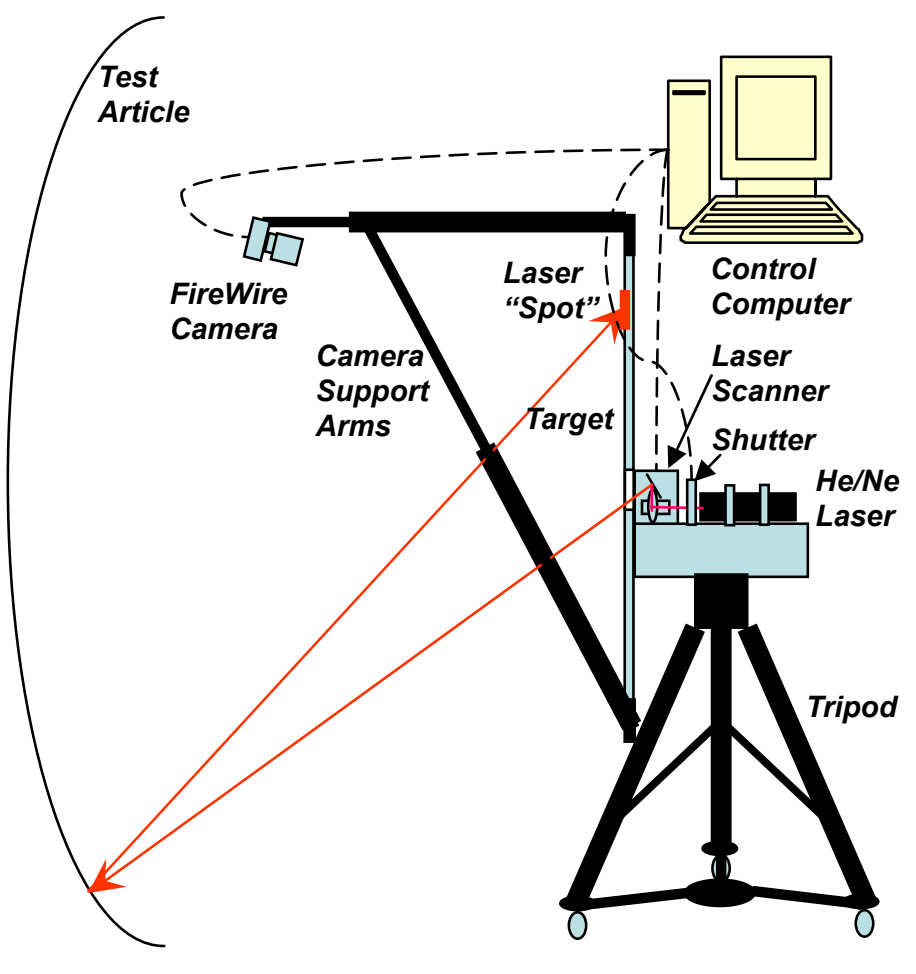

Figure 1. Schematic of the VSHOT system and test article with unknown curvature.

The heart of the VSHOT system is a Class IIla HeliumNeon laser that emits a visible beam at a wavelength of 633 nanometers (red light). The Class IIla laser is not focused and therefore does not require any significant hazard controls.

The emitted laser beam passes through a computercontrolled shutter and proceeds into a turning mirror, which redirects the beam into a computer controlled $X-Y$ scanning unit. This unit subsequently outputs the beam anywhere inside an approximately $80^{\circ}$ full cone angle. The complete laser-scanning unit is mounted onto a movable, adjustable tripod for alignment purposes. This unit goes through a one-time calibration process in which the digital position ( 0 to 65,535) in both the $x$ and $y$ directions is mapped to the angles of the outgoing beam in both the $x$ and $y$ directions. The outgoing beam from the laser scanner passes through a hole in a flat square target attached to the front of the laser scanner assembly. The beam is directed to a user-defined point (via computer control) on the test article. The test article reflects the beam back towards the laser scanner. Ultimately the reflected beam hits the large square target mounted to the front of the laser scanner tripod assembly. 
When the reflected beam from the test article intersects the white front surface of the target, it results in a red "spot" on the target. The "spot" size and shape is a function of the microscopic surface quality of the reflecting test article. The location of the spot centroid on the target is a function of the macroscopic surface contour, position and orientation relative to the VSHOT optical axis and source position. A digital, computercontrolled FireWire camera mounted to the front of the target via adjustable support arms looks back at the target and images the entire target including the laser "spot". The camera goes through a calibration process similar to the laser scanner in which the camera's digital pixel array is mapped to the Cartesian coordinate system of the flat target. This is done once for each initial setup of the VSHOT. Thereafter, the support arms lock the camera in place relative to the target. Camera calibration is not needed again unless the camera is repositioned relative to the target. This is a recent refinement, allowing more rapid data collection in the field. It should be noted that the system has been used when the ambient temperatures are comfortable enough for the user. To date, the system has been used successfully between $50^{\circ} \mathrm{F}$ and $85^{\circ} \mathrm{F}$. VSHOT tests have been attempted at temperatures approaching $100^{\circ} \mathrm{F}$ and beyond, but the laser scanner electronic control did not operate in a stable fashion at these temperatures. The system operators did not fair well at these temperatures either. In these cases, testing was performed later in the day after temperatures had fallen into the above range. Both the laser scanner and the video camera are very stable over this temperature range. A complete analysis of the measurement uncertainty has been performed and described in a previous paper. ${ }^{2}$

\section{DATA COLLECTION PROCESS}

The laser scanning system is assumed to have already gone through the one-time calibration where outgoing beam angles are mapped to the digital positions of the X-Y scanning mirrors. As mentioned previously, the VSHOT was originally designed to test point-focus optics. The nature of a point-focus concentrator is such that the entire aperture (in $\mathrm{X}$ and $\mathrm{Y}$ ) can be tested, because the return beams all come back to a practically sized target. However, it is not practical to test the entire aperture of a trough concentrator with this system, because the single curvature optics would require an extremely large target. The VSHOT can be used, however, to do profiles (vertical slices) across the aperture width at multiple locations along the concentrator length. The analysis is then restricted to the vertical or $\mathrm{Y}$ direction contour. Error in the horizontal or $\mathrm{X}$ direction is not considered, because errors in this direction result in rays that should still hit the receiver just left or right of where they would have otherwise.
Many such profiles can be averaged to yield a good characterization of the overall optical performance. Individual profiles provide detailed information concerning mirror facet contour and alignment.

The trough concentrator is pointed toward the horizon. The VSHOT is positioned at a little greater than twice the expected trough focal length away from the trough vertex (2f). This distance is measured with a laser range finder. With the point source at this distance, the extent of the return "spot" pattern just fills the target (for an ideal parabola). The system is leveled, and the height is adjusted to match the height of the concentrator vertex. The ideal trough geometry (i.e. aperture width and focal length), the region of interest and the number of data points to scan inside that region are defined in the VSHOT control software. Via control software, the operator then directs the computer-controlled laser scanner to draw an outline of the region of interest (vertical strip) on the parabolic trough concentrator. The pattern of return "spots" is observed on the target to verify that the VSHOT system is properly aligned and centered on the test article, and that the pattern fills the target. If this is not the case, then appropriate adjustments are made to accomplish this (i.e. tilt and/or translation of the trough concentrator and/or the VSHOT). Because the process centers the return distribution on the target, the overall tilt of the concentrator is minimized. The data then provide the best assessment of the contour itself, which is the desired result.

Once the VSHOT system is aligned with the optical axis of the trough, the position and zoom of the camera are physically adjusted to image the target. The camera is then locked into place using the support arms. A calibration using a target grid is performed to map the spatial $X-Y$ coordinate system of the target plane field of view to the camera's pixel array. The camera is now physically tied to the target eliminating the need to redo the camera calibration every time the complete system is moved. Various camera parameters, including aperture size and integration time, are then adjusted so that the camera "sees" only the return "spots" on the target and not other extraneous light sources. If tests are done in the field during the day, a He/Ne pass-band filter may be used to eliminate transient lighting conditions.

Once the setup and pertinent calibrations have been accomplished, the operator begins the test. The computer tells the laser scanner to direct the beam to the first data point on the test article. The digital camera is then directed by the computer to take an image of the target with the reflected "spot". A previously obtained background image is subtracted from the image with the laser "spot" and the imaged is further thresholded by a previously determined value. What remains is an image 
consisting of the laser "spot" on a black background. During the day, a $\mathrm{He} / \mathrm{Ne}$ passband filter is used to eliminate transient background effects, so this background does not change significantly with time. However, if lighting conditions have changed significantly, or if the filter is not used, a new background image is taken periodically. The computer analyzes the image and calculates the spatial position of the "spot" centroid in the target plane's X-Y coordinate system. Once the computer is satisfied that the data point information has been properly recorded (i.e., outgoing laser direction angles, return "spot" location coordinates on the target and "spot" intensity), it directs the laser scanner to proceed to the next data point. This procedure is automatically repeated by the computer until the entire region of interest has been scanned. The number of datum points depends on the quality of the surface being tested. For glass trough mirrors, multiple tests have shown that a spacing of 0.5 inches is sufficient to capture the relevant features. In actuality, the region of interest is not a one-dimensional vertical strip, but rather a narrow rectangle the width of which equals the desired spacing. This is an artifact of the original point focus analysis. The vertical error analysis is not affected. Thus for every vertical position there are two data points side by side. For a trough with a 5-meter aperture width this translates into roughly 2000 data points. Upon test completion, the computer prompts the operator to save the data to a file for subsequent analysis. This completes the data acquisition process. The operator can then proceed with the data analysis part of the VSHOT software if desired or move down the trough concentrator length to the next location for a new data profile.

\section{DATA ANALYSIS}

The raw data is processed to provide useful information concerning the optical surface shape.

The data file contains the geometry setup information including the measured distance of the target from the trough vertex and the desired focal length assuming an ideal parabola. The outgoing beam angles and the $X-Y$ position of the return spot on the target are recorded for every data point. For each data point, the computer calculates where on the target the "spot" should be located, if the trough contour where ideal. For each data point, two surface slopes are calculated: one for the ideal shape and one from the actual position of the return beam on the target. The difference is calculated for each data point and included in a root-mean-square calculation to provide an overall value of the departure of the actual contour from the ideal.

The actual surface is described mathematically by the following equation ${ }^{3}$ :

$$
Z(x, y)=\sum_{i=0}^{k} \sum_{j=0}^{i} B_{i, j} x^{j} y^{i-j}
$$

An iterative least-squares process is used to minimize the overall R.M.S slope difference (error) resulting in the best-fit equation. Since the ideal trough concentrator is a parabola, only a $2^{\text {nd }}$ order fit is used. Thus, the coefficients that are allowed to change include the terms $B_{1,0}, B_{1,1}, B_{2,0}, B_{2,1}$ and $B_{2,2}$. In the case of a single-axis concentrator, only the $B_{1,0}$ term $=$ tilty and the $B_{2,0}=1 /\left(4 f_{y}\right)$ terms are relevant. The user can choose to fix either or both of these, if desired, or allow all terms to adjust. The R.M.S. slope error is then a useful figure of merit for comparing the best-fit shape with the desired ideal parabola. Again, only the vertical component of the slope error (dZ/dY) is of interest, so the two directional contributions to the error are separated. In addition to the best-fit equation and the R.M.S. slope error, the difference in vertical slope between actual and ideal for each data point can be plotted as a function of $Y$. This provides immediate and informative feedback as to the departure of the actual contour from the ideal.

Figure 2 shows the summary of a VSHOT fit analysis for a typical trough test: 


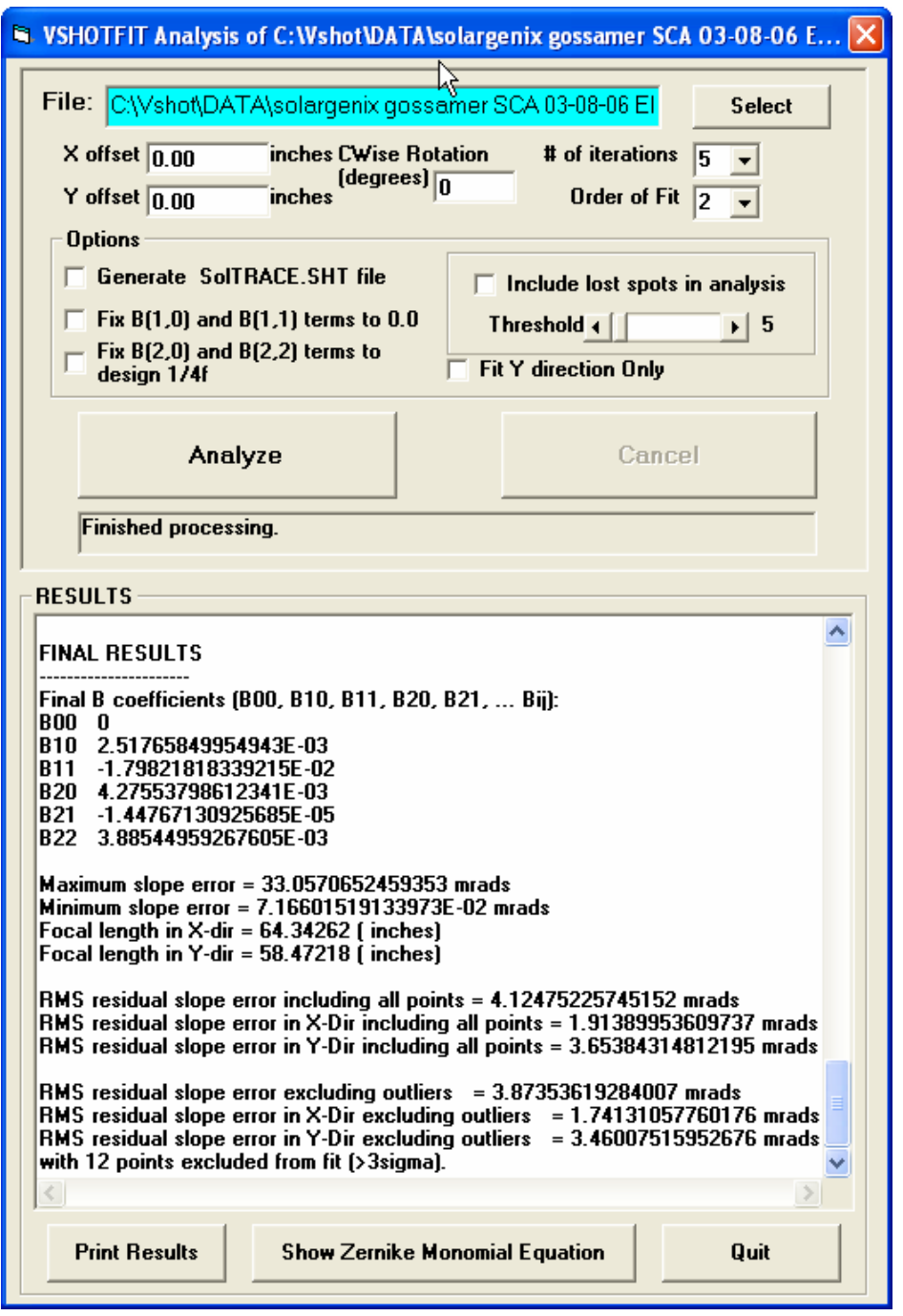

Figure 2. Example of VSHOT fit analysis for typical trough test.

\section{TEST RESULTS FOR SOLARGENIX $1^{\text {ST }}$ AND $2^{\text {ND }}$ GENERATION DESIGNS}

Solargenix has been developing a trough concentrator over the past several years with the goal of manufacturing and installing it in their first power plants. Solargenix began with the basic geometry of the LS-2 concentrator, manufactured and installed by LUZ at the SEGS plants in Southern California. Solargenix has maintained this geometry throughout the evolution of their design. This choice was based largely on industry and operational experience with the LS-2 concentrator. The LS-2 has demonstrated good performance and maintainability since it's installation in the 1980's. However, Solargenix has made significant changes to the support structure and drive system with the goal of reducing cost while maintaining or improving performance. Also, Solargenix has doubled the overall length of its Solar Collector Assembly (SCA) compared to the LS-2. The Solargenix design incorporates the same glass mirrors used in the LS-2. Solargenix has looked at different mirror constructions including composite and metal substrates ${ }^{4}$, but these approaches require more development and will not be pursued for use in their initial plants.

A prototype of their first design iteration was built and tested with the VSHOT in 2004. This was the first such VSHOT test performed outdoors and demonstrated the usability of the instrument under these conditions. These tests demonstrated that the basic design was capable of meeting their optical specifications, but also that improvements could be made that would reduce part count, installation time and cost, as well as improve performance. Specifically, individual panel tilt/misalignment was observed, which could be minimized through adjustments. The source of this tilt needed to be understood in order to minimize or eliminate it in subsequent designs.

A full SCA test string utilizing this design was installed In Eldorado Valley near Boulder City, Nevada. This site has proved invaluable to Solargenix in the development and testing of their concentrator. In February of 2005, VSHOT tests were performed on the 1st generation design. The goal of the VSHOT tests was to further evaluate the optical quality of the design and determine whether additional field adjustments might be warranted to achieve additional optical accuracy.

Testing occurred over the course of a late afternoon/evening session and a daytime session. At this time, only a limited number of mirrors had been installed on the concentrator. The Solargenix trough module aperture width spans four separate glass panels, two identical inner panels and two identical outer panels installed symmetrically on both sides of the vertex. Vertical VSHOT data profiles spanning the aperture width were collected on three separate columns of glass mirror panels. The VSHOT then analyzed this data to determine overall optical shape relative to the ideal parabolic contour and also the shape and tilt of each individual panel relative to the ideal. Results indicate that, while there were modest variations in the three sets of panels, as installed, panel alignment/tilt was now within Solargenix's specification. Based on this result, field adjustments were not expected to be necessary, however more testing would be required to understand the source of the mirror panel tilt and continue to improve on it. Figure 3 shows the original VSHOT test setup at the Eldorado Valley site with the camera independent of the target. The camera calibration grid can be seen on the target to the right. Since this time, a new target/camera mounting system has been implemented that integrates the camera to the target via support arms necessitating only one camera calibration per session. 


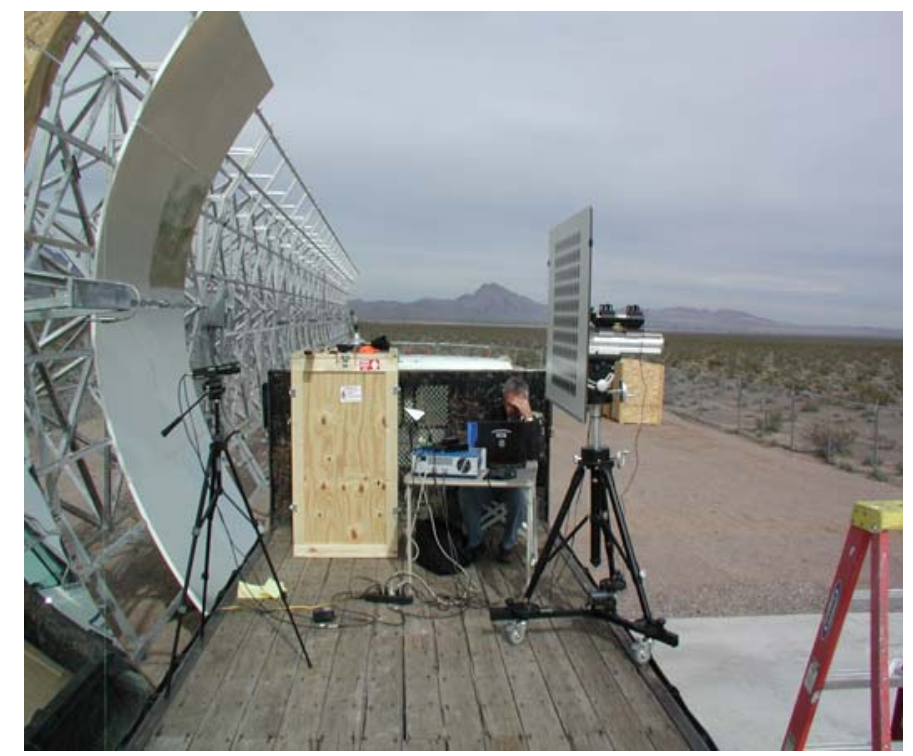

Figure 3. The VSHOT test setup at the Solargenix Test Loop in Boulder City, Nevada.

By July 2005, the entire test string had been fitted with mirrors providing the opportunity to VSHOT test an entire SCA. Testing occurred over the course of a late afternoon to early morning session between $5: 00 \mathrm{pm}$ and 3:30am. High temperatures $\left(>100^{\circ} \mathrm{F}\right)$ and evening winds (in excess of 30 miles per hour) limited the test windows to this one time slot. The system can operate in moderate winds of 10-20 miles per hour

As mentioned previously, the Solargenix trough module 5meter ( 200 inches) aperture width spans four separate glass panels, two inner panels and two outer panels installed symmetrically on both sides of the vertex. There are five such mirror columns per module. An SCA consists of twelve modules, six on each side of the drive. Vertical VSHOT data profiles spanning the aperture width were collected on two randomly selected columns per module. Time did not allow testing each mirror column of the SCA. In all, twenty-six scans were performed including some repeat scans taken after module alignment adjustments had been made. The VSHOT software was used to analyze the data to determine overall optical R.M.S. slope error relative to the ideal parabolic contour and also provided additional information on the shape and tilt of each individual panel relative to the ideal. A summary of the results is presented in Figures 4-6.

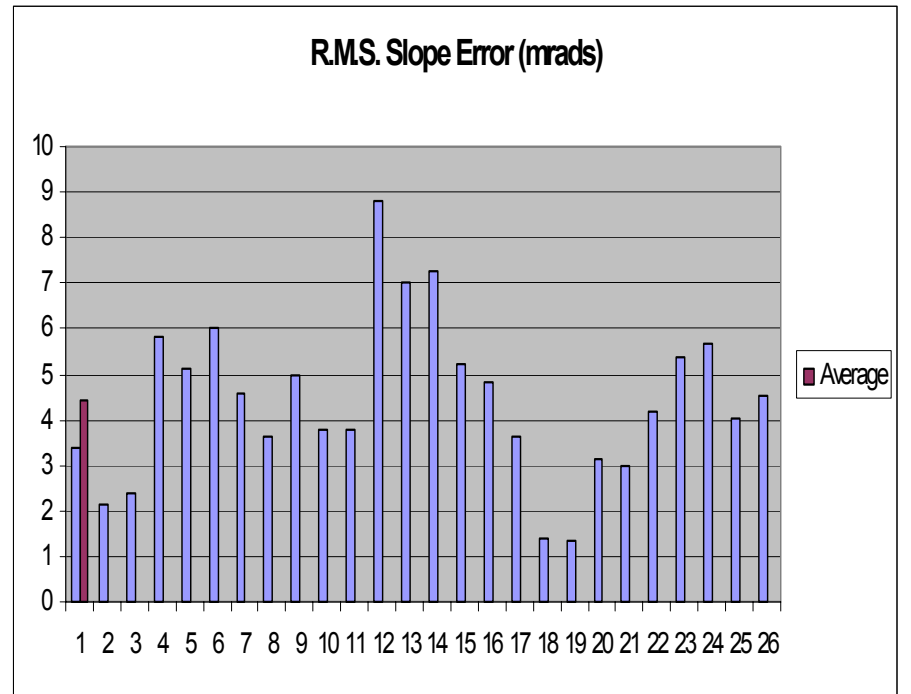

Figure 4. R.M.S. Slope Error for each of the 26 scans and the average of all scans.

Figure 4 is a bar chart of the R.M.S. Slope Error for each of the 26 scans taken along the full length of the SCA. The focal length term in the calculation was allowed to vary in this analysis. Although there is considerable variation, the overall average of 4.4 milliradians is less than the 5.0 milliradian Solargenix specification. Figure 5 presents the best-fit focal length for each scan. Again, some variation exists between a minimum of roughly 58.2 inches and a maximum of 59.2 inches, but the overall average is right on the design value of 58.7 inches.

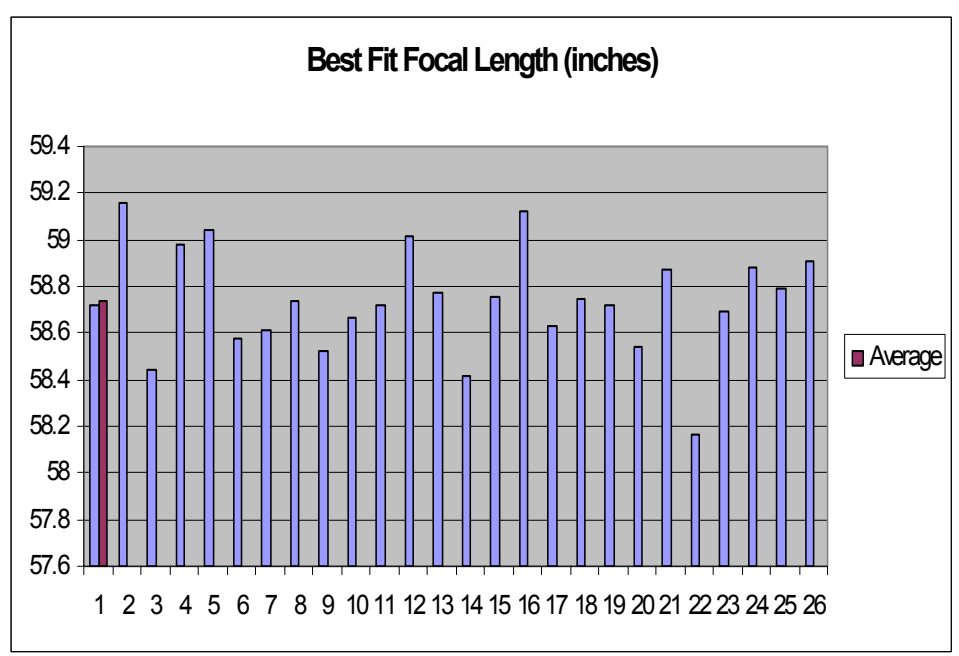

Figure 5. Best-fit focal length for each of the 26 scans and the average of all scans.

Figure 6 presents the same analysis, however the focal length has been fixed to the design value. As expected, 
the overall average R.M.S. slope error increases, but only slightly to an average value of 4.8 milliradians.

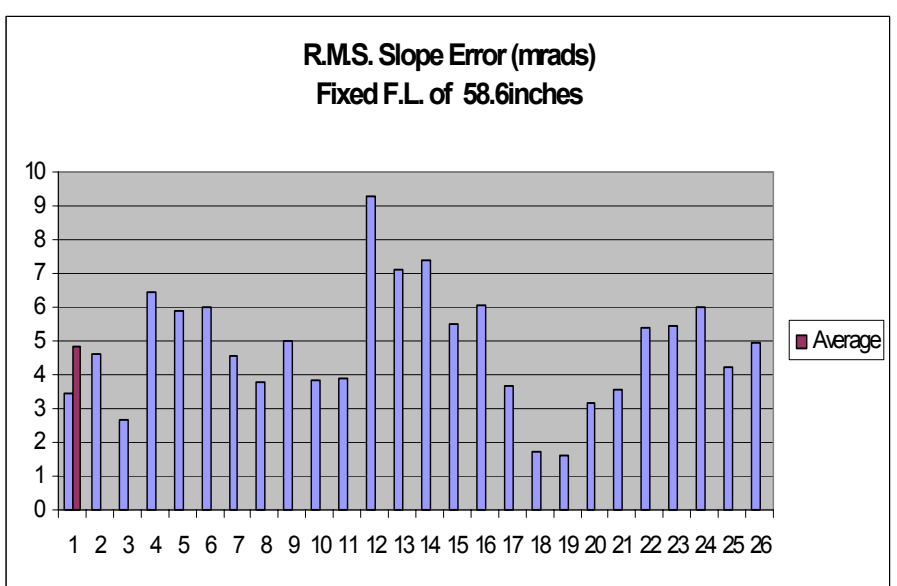

Figure 6. R.M.S. slope error for each of 26 scans fixing the focal length to the desired focal length and the average of all scans.

Figure 7 is a plot of the slope error as a function of vertical position across the aperture for Scan 1 . In this case the R.M.S. slope error for the scan was 3.4 milliradians. The features seen in this plot are typical of all scans and contain both contour errors in the glass, mirror panel tilt, and discontinuities at the edges of each glass panel.

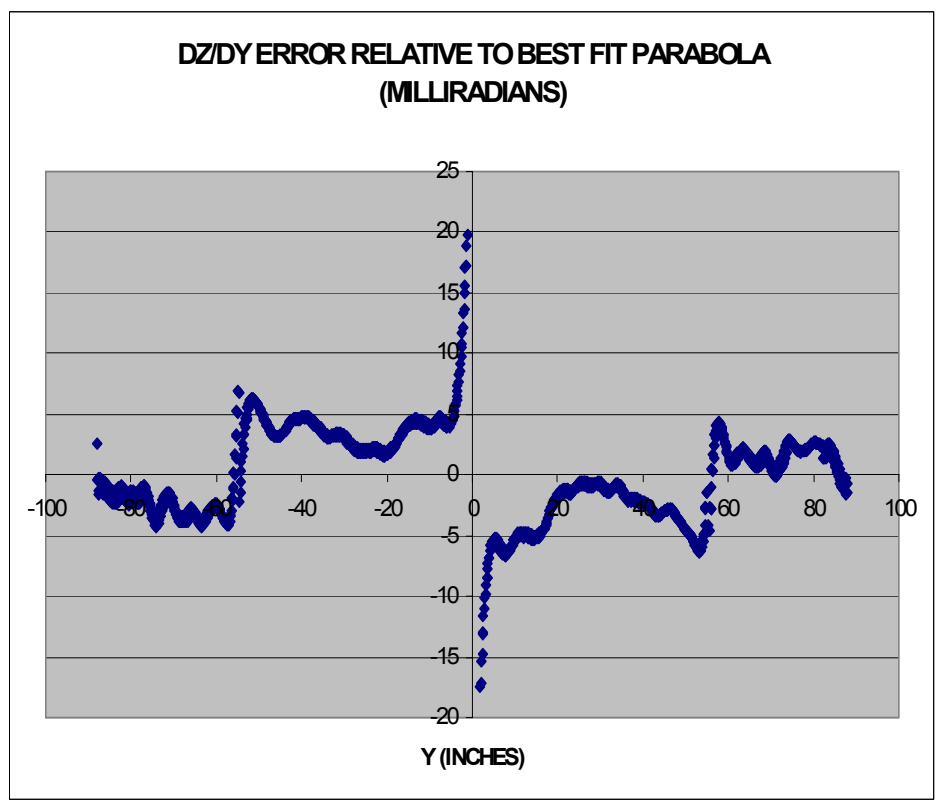

Figure 7. Typical plot of the slope error relative to best-fit parabola vs. position across the aperture.
All four panels can be distinguished beginning with the outermost lower panel on the left. The inner panels extend from 0 to \pm 56 inches. A relatively flat, but nonzero slope error would be an indication of panel tilt relative to ideal. The higher frequency features are features present in the glass. One commonality observed among all glass panels was the localized higher curvature at each edge resulting in spikes in the error relative to the ideal shape. Although very evident in the plots, the amount of actual aperture area involved is so small that it doesn't affect the overall R.M.S. slope error that significantly.

Based partly on these results and on the desire to further reduce part count and assembly time/labor, Solargenix developed a next generation concentrator design. Under an Advanced Component subcontract with NREL, Solargenix developed an alternative, low-cost trough design for parabolic trough concentrating collectors. The new design is an advanced hub-based, field-assembled space frame. The new design resulted in more than a $20 \%$ weight reduction compared to the prior-generation Solargenix space frame and a significantly reduced part count, which Solargenix expects to translate into significant installed cost reductions.

Several prototypes, constituting two generations of the new space frame were fabricated, and one of them installed at the Eldorado Valley test site. This module was tested on two separate occasions with the VSHOT in October 2005. The test results show that it has excellent optical accuracy approaching 3.0 milliradians while also exhibiting less variability from mirror column to mirror column. This design has the potential to significantly reduce assembly time and may, in fact, require little or no mirror adjustment. These results led Solargenix to use this design in the 64MW plant, which they will begin building early in 2006 .

\section{TEST RESULTS FOR INDUSTRIAL SOLAR TECHNOLOGY TROUGH CONCENTRATOR}

Industrial Solar Technology Corporation (IST) has a subcontract with the DOE CSP subprogram through NREL to develop a larger-scale version of their already successful trough concentrator used for process heat applications. This new design would compete in the electric power generation market. Phase I of the subcontract involves conceptual design and analysis. If successful, Phase II would result in a prototype for testing. As part of Phase I, a performance baseline of IST's current standard trough concentrator design was required. VSHOT tests were performed on two separate occasions. The first set of tests was done on a module utilizing optical reflector film. This is the standard material used by IST. Because IST is interested in using glass 
mirrors for the larger module design, the second set of tests was done on the same module using thin glass tiles. The IST approach is considerably different than the Solargenix design in that the concentrator is a single surface metal substrate/mirror laminate, which itself becomes the support structure when combined with structural cross members across the aperture. Potential advantages include highly efficient use of materials and elimination of individual mirror misalignment, effectively lowering cost and maintaining or increasing performance. Figure 8 is a picture of the VSHOT/IST trough module setup at IST's facility in Golden, Colorado and provides a good view of the IST concentrator. Ten profiles were taken along the length of the module in the first round of testing (optical reflective film). A summary of the results is shown in Figures 9-11. Figure 9 is a summary of the R.M.S. slope error relative to the best-fit parabola allowing the focal length to change. The average of all the scans is 4.5 milliradians, which is considered acceptable for solar process heat applications. The bestfit focal length is shown in Figure 10. The focal lengths for each profile vary between 29.8 and 30.1 inches with the average being 29.9 inches. This is less than the design focal length of 30.35 ". Figure 11 is a plot of the slope error as a function of vertical position across the aperture. All of the scans exhibited the same basic profile demonstrating the consistency inherent in this continuous surface design (no individual mirror panels). The slope error increases near both edges indicating a flattening of the surface relative to the ideal parabola. IST acknowledges this feature and has ideas to improve on it in the next design iteration. Overall, IST is very pleased with these results for their baseline concentrator.

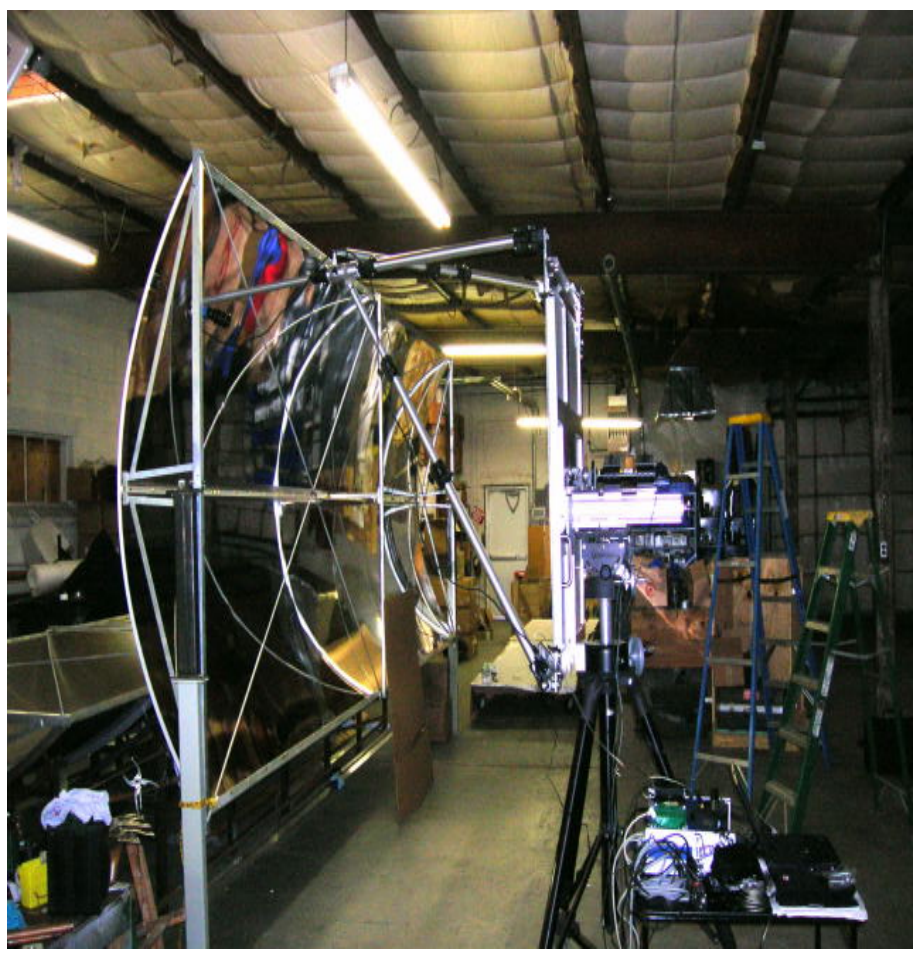

Figure 8. The VSHOT test setup at Industrial Solar Technology's facility in Golden, Colorado.

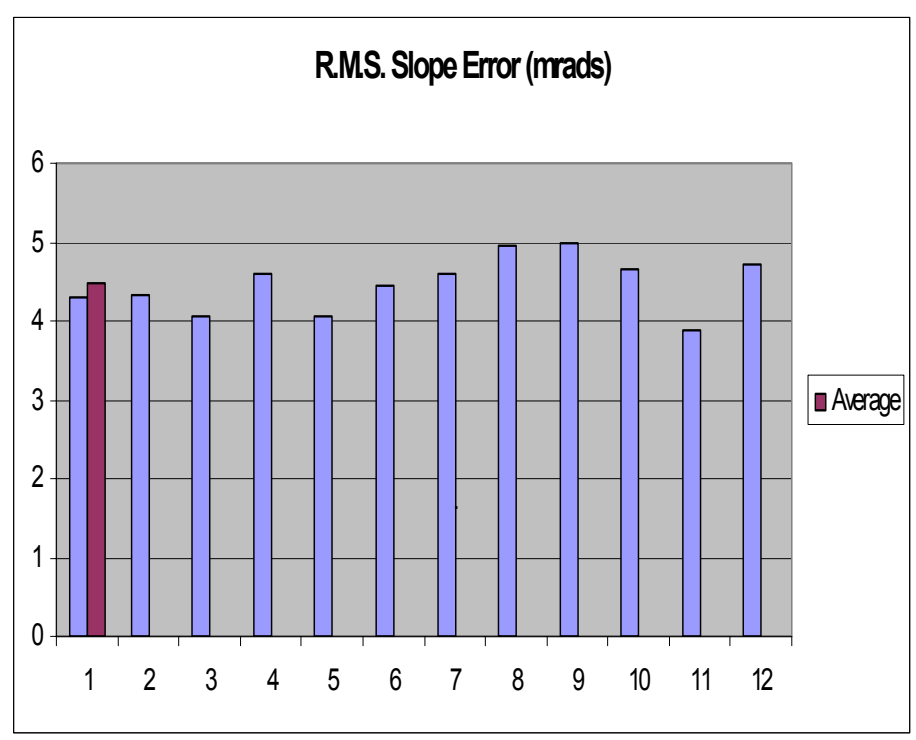

Figure 9. R.M.S. Slope Error for each of the 12 scans and the average of all scans. 


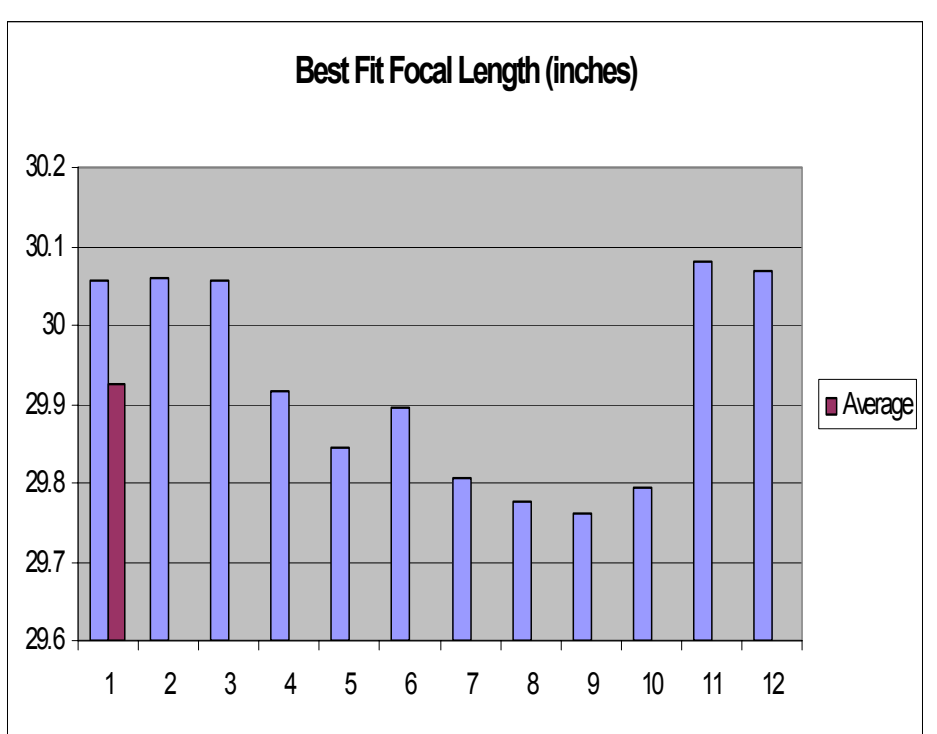

Figure 10. Best-fit focal length for each of the 12 scans and the average of all scans.

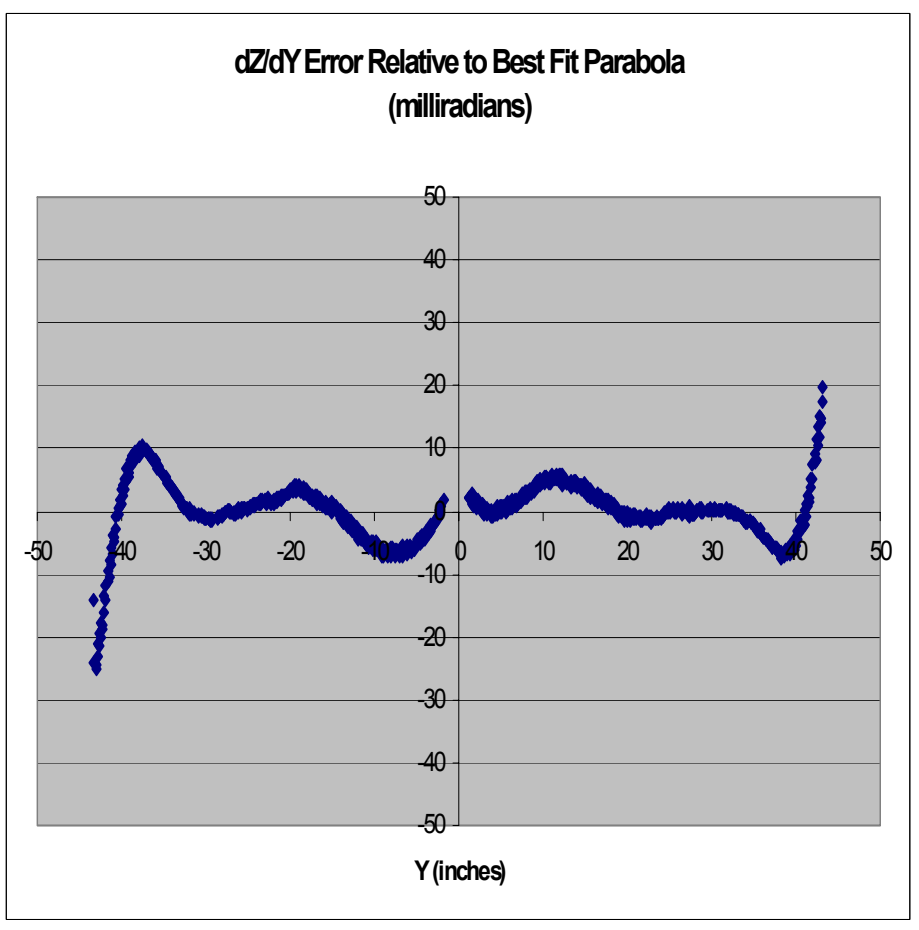

Figure 11. Typical plot of the slope error relative to best-fit parabola vs. position across the aperture.

\section{SUMMARY}

The VSHOT has proven to be a very useful instrument in the continued development and improvement of parabolic trough concentrator technology. Modifications and changes to the system have made it a valuable instrument for those designs already implemented in the field as well as those designs still in the research and development stages. Test results have enabled Solargenix to confidently move forward with the $2^{\text {nd }}$ generation concentrator in their next power plant and have provided IST with an understanding of their baseline design, which they hope can be scaled up to a concentrator suitable for electric power generation. In the future, the VSHOT will continue to be used in support of both of these efforts as well as to benchmark new optical testing techniques being developed in 2006.

\section{REFERENCES}

1. Jones, S.A., "VSHOT Measurements of DISTAL II Dish Concentrators", Proceedings of the Renewable and Advanced Energy Systems for the $21^{\text {st }}$ Century, a joint ASME/JSME/JSES/KSME International Conference, April 11-15, 1999, Maui, Hawaii.

2. Jones, S.A. Gruetzner, J.K., Houser, R.M., Edgar, R.M., Wendelin, T.J., 1997, "VSHOT Measurement Uncertainty and Experimental Sensitivity Study", Proceedings of the 32nd Annual Intersociety Energy Conversion Engineering Conference, Vol. 3, pp. 1877-1882.

3. Malacara, D., 1978, Optical Shop Testing, John Wiley \& Sons, Inc.

4. Wendelin, T. and Gee, R., 2004, "Optical Evaluation of Composite-Based Reflector Facets For Parabolic Trough Concentrators", Proceedings of the ASME International Solar Energy Conference 2004, Paper \# ISEC200465151. 


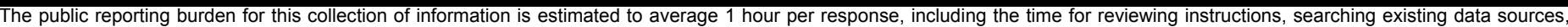

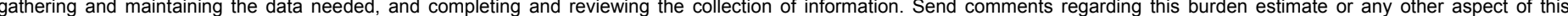

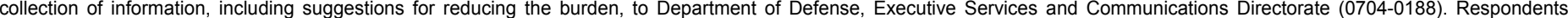

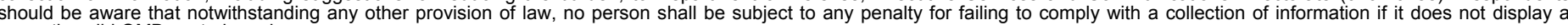
currently valid OMB control number.

PLEASE DO NOT RETURN YOUR FORM TO THE ABOVE ORGANIZATION.

\section{REPORT DATE (DD-MM-YYYY) June 2006}

4. TITLE AND SUBTITLE

Video Scanning Hartmann Optical Testing of State-of-the-Art

Parabolic Trough Concentrators: Preprint
3. DATES COVERED (From - To)

5a. CONTRACT NUMBER

DE-AC36-99-GO10337

5b. GRANT NUMBER

5c. PROGRAM ELEMENT NUMBER

5d. PROJECT NUMBER

NREL/CP-550-39590

5e. TASK NUMBER

CP06.5002

5f. WORK UNIT NUMBER
7. PERFORMING ORGANIZATION NAME(S) AND ADDRESS(ES)

National Renewable Energy Laboratory

1617 Cole Blvd.

Golden, CO 80401-3393
8. PERFORMING ORGANIZATION REPORT NUMBER

NREL/CP-550-39590

9. SPONSORING/MONITORING AGENCY NAME(S) AND ADDRESS(ES)

10. SPONSOR/MONITOR'S ACRONYM(S) NREL

11. SPONSORING/MONITORING AGENCY REPORT NUMBER

12. DISTRIBUTION AVAILABILITY STATEMENT

National Technical Information Service

U.S. Department of Commerce

5285 Port Royal Road

Springfield, VA 22161

\section{SUPPLEMENTARY NOTES}

14. ABSTRACT (Maximum 200 Words)

This paper describes the Video Scanning Hartmann Optical Test System (VSHOT) used to optically test parabolic trough designs by both Solargenix and Industrial Solar Technology.

15. SUBJECT TERMS

Concentrating solar power; parabolic solar trough; parabolic trough

\begin{tabular}{l}
\hline \multicolumn{3}{|l|}{ 16. SECURITY CLASSIFICATION OF: } \\
\hline \begin{tabular}{l|l|l|} 
a. REPORT & b. ABSTRACT & c. THIS PAGE \\
Unclassified & Unclassified & Unclassified \\
& & \\
\hline
\end{tabular} \\
\hline
\end{tabular}

17. LIMITATION
OF ABSTRACT
UL

18. NUMBER OF PAGES 19a. NAME OF RESPONSIBLE PERSON

19b. TELEPONE NUMBER (Include area code) 